\title{
Simple synthesis-controlled fabrication of thallium cadmium iodide nanostructures via a novel route and photocatalytic investigation in degradation of toxic dyes
}

\author{
Mojgan Ghanbari ${ }^{\mathrm{a}}$, Fatemeh Ansari ${ }^{\mathrm{b}}$, Masoud Salavati-Niasari ${ }^{*}$ \\ ${ }^{a}$ Institute of Nano Science and Nano Technology, University of Kashan, Kashan, P. O. Box. 87317-51167, I. R. \\ Iran \\ ${ }^{b}$ Faculty of Science, Islamic Azad University, Science and Research Branch, Tehran \\ * Corresponding author. Tel.: +9831 55912383; Fax: +983155913201 \\ E-mail address: salavati@kashanu.ac.ir (Prof. Masoud Salavati-Niasari)
}

\begin{abstract}
The present work focused on the synthesis and characterization of $\mathrm{TlCdI}_{3}$ nanostructures through a new mechanical mixture of the reactants method for the first time. In this work, thallium nitrate, cadmium nitrate and lithium iodide were chosen as starting reagents. The preparation of $\mathrm{CdI}_{2}$ and $\mathrm{TlI}$ for synthesis of $\mathrm{TlCdI}_{3} \mathrm{were}$ performed at ambient condition. The morphology, phase structure, and phase purity of $\mathrm{TlCdI}_{3}$ can be controlled by the TII:CdI 2 ratio and also adjusting type of surfactant. In our experimental conditions, the ideal ratios between T1I:CdI 2 was 1:1, Also the ideal surfactant was SDS. The nanostructures were characterized by using XRD, SEM, TEM, EDS and FT-IR. The photocatalytic activity of the synthesized products has been compared in the photodegradation activity of methyl orange (MO) and methylen blue (MB).
\end{abstract}

Keywords: Nanostructure; $\mathrm{TlCdI}_{3}$; Surfactant; Photocatalytic; Optical property; Electron microscopy.

\section{Introduction}


In recent years Metal halide perovskites are currently under intense investigations because of their potential application in photoelectronic devises [1-4] and as light emitting diodes, photodetectors, and lasers [5-8]. The perovskite structure is a highly versatile and widespread mineral form, of great importance in nature and technology. They were first suggested by the Russian mineralogist Count Lev Aleksevich von Perovski, who discovered the naturally occurring mineral calcium titanate $\left(\mathrm{CaTiO}_{3}\right)$ [9]. The stability of pervoskite structure is necessary for this the sum of positive and negative charges be equal to the crystal lattice charge becomes zero. In halide Perovskite the sum of halide ions charge is equal to -3 , as a result the sum of cations charge must be equal to $+3[9,10]$. Many halide perovskites with the general formula $\mathrm{AMX}_{3}(\mathrm{~A}=\mathrm{Cs}, \mathrm{Rb} ; \mathrm{Tl} ; \mathrm{M}=\mathrm{Cd}, \mathrm{Mg}, \mathrm{Ni} ; \mathrm{X}=\mathrm{Cl}$, $\mathrm{Br}$, I) are built face-shared, corner-shared,edge-shared orpartlyface-partly corner-shared form of $\left[\mathrm{MX}_{6}\right]_{4}$ octahedrons [11-14] of special interest are the group 14 iodometalates, since they can adopt perovskitic structures that are amenable to compositional variation. In the perovskite formula, $\mathrm{AMX}_{3}$, when the A-site in structure, is occupied by a small monovalent cation, such as $\mathrm{Rb}, \mathrm{Cs}, \mathrm{K}$ is obtained a three-dimensional (3D) framework [15, 16]. If a larger cation is used instead two-dimensional (2D) layered [17, 18] or one-dimensional (1D) chain [19, 20]. Materials are obtained with formulas $\mathrm{AMI}_{3}, \mathrm{~A}_{2} \mathrm{MI}_{4}$ and $\mathrm{A}_{3} \mathrm{MI}$ which still retain their perovskite [21, 22]. The structure of these compounds is extremely dependent on the stoichiometry of the final material and the metalhalide linkages [23].

Nanomaterials have been synthesized by hydrothermal [24], reverse-micelle [25], chemical co-precipitation [26], auto-combustion sol-gel technique [27-30], glass-crystallization [31], and salt melt methods [32]. But precipitation is an effective method for the synthesis because this technique provides a simple and appropriate approach for preparation of nanometerials and has many advantages: low cost, easy component adjustment, and high homogeneity of the obtained nanomaterials [33]. In this work the nanostructures of $\mathrm{TlCdI}_{3}$ were synthesized by simple mechanical mixture of the reactants method in ambient condition, Accordingly, neither high- 
temperature, complex chemical reactions nor high-vacuum deposition processes are required, contrary to most conventional methods that have been used for synthesis these materials. Finally products were characterized by XRD, SEM, TEM, EDS, FT-IR, DRS and UV-Vis

\section{Experimental}

\subsection{Materials and experiments}

All the chemicals used in our experiments were of analytical grade, were purchased from Merck and used as received without further purification. XRD patterns were collected from a diffractometer of Philips Company with X'PertPro monochromatized $\mathrm{Cu} \mathrm{K} \alpha$ radiation $(\lambda=1.54 \AA \AA$ ). GC-2550TG (Teif Gostar Faraz Company, Iran) were used for all chemical analyses. FE-SEM images were obtained on MIRA3 FEG-SEM.. The EDS analysis was studied by XL30, Philips microscope.

\subsection{Synthetic of $\mathrm{TlCdI}_{3}$}

$\mathrm{TlCdI}_{3}$ has been synthesized from precorsur $\mathrm{TII}$ and $\mathrm{CdI}_{2}$. For synthesis of TlI stoichiometry amount of $\mathrm{TlNO}_{3}$ and LiI were dissolved in separate Beakers in distilled water. The preparation of $\mathrm{CdI}_{2}$ is similar to TII for this point $\mathrm{Cd}\left(\mathrm{NO}_{3}\right)_{2}$ was used as $\mathrm{Cd}$ source and stoichiometry amount of $\mathrm{Cd}\left(\mathrm{NO}_{3}\right)_{2}$ and LiI were dissolved in separate Beakers in distilled water to form a clear solution. Following TII and $\mathrm{CdI}_{2}$ were mixed together with a curtained ratio and grinned in mortar for $2 \mathrm{~h}$ and the result powder were dried in oven at $70{ }^{\circ} \mathrm{C}$. the effect of different parameters was investigated on the morphology and phase purity of the products. Table 1 lists the reaction conditions for the synthesis of $\mathrm{TlCdI}_{3}$. Scheme 1 shows a schematic diagram of the formation process of the $\mathrm{TlCdI}_{3}$ nanostructures.

\subsection{Photocatalytic experiment}


The photocatalytic activities of the samples are determined by the degradation of aqueous methyl orange (MO) and methylene blue $(\mathrm{MB})$ under UV light in presence of $\mathrm{TlCdI}_{3}(0.005 \mathrm{~g} / \mathrm{L})$ is first inserted to a reactor that included about $(0.1 \mathrm{mM})$ of aqueous $\mathrm{MO}$ and $\mathrm{MB}$. Then the suspension is transferred into a self-designed glass reactor, and stirred in darkness to attain the adsorption equilibrium. In the investigation of photodegradation using UV light, a $125 \mathrm{~W}$ high-pressure mercury lamp with a water cooling cylindrical jacket is utilized. The concentration of $\mathrm{MO}$ and $\mathrm{MB}$ is checked on the basis of its UV-visible absorption.

\section{Results and discussion}

XRD analysis, which is the most useful technique for identification of crystalline structure, was employed to investigate the prepared samples. The XRD patterns for the samples no: 1, 2, 3 and 4 are shown in Fig. 1a-d, respectively. When the ratio of $\mathrm{TII} / \mathrm{CdI}_{2}$ is $1: 1$ and 1:0.75 (sample no. 1 and 4), the products have the peaks corresponding to pure $\mathrm{TlCdI}_{3}$ (JCPDS NO 70-2182), as shown in XRD patterns in Fig. 1a. Changing of the ratio of TlI/ $\mathrm{CdI}_{2}$ from 1:1 to 2:1 (sample no. 2) and 1:2 (sample no. 3), a mixture of $\mathrm{TlCdI}_{3}$ and $\mathrm{Tl}_{4} \mathrm{CdI}_{6}$ (JCPDS NO 791303), in Fig. $1 \mathrm{~b}$ and $\mathrm{TlCdI}_{3}$ and $\mathrm{CdI}_{2}$ (JCPDS NO 33-0239) in Fig. 1c are obtained respectively.

In the following the effect of surfactants (NaHSal, CTAB, SDS, Triplex and PVA) on the purity of the products were investigated. Fig. 2a-f shows the XRD patterns of products (sample no. 5, 6, 7, 8 and 9) obtained in the presence of different surfactants. This figure clearly shows the formation of $\mathrm{TlCdI}_{3}$ only occur in the presence of SDS.

The morphology of the samples was investigated by SEM images. Fig. 3 shows the SEM images of samples achieved with different ratios of $\mathrm{TlI} / \mathrm{CdI}_{2}$ involving (a) 1:1, (b) 2:1, (c) 1:2 and 1:0.75 (d). It can be seen that the bulk structures are formed when the molar ratio of $\mathrm{TII} / \mathrm{CdI}_{2}$ is 2:1 and 1:0.75 (sample no. 2 and 4). The spherelike nanostructures in sample no. 1 and 3 are aggregated as shown in Fig. $3 \mathrm{c}$ and d, whereas in the sample no. 1 
these structures are apart from one another (Fig. 3 c). Thus, in our experimental conditions, the ideal ratio between $\mathrm{TII} / \mathrm{CdI}_{2}$ is $1: 1$. In continuation, the effect of the surfactant on the morphology of the products was investigated, whereas the molar ratio between $\mathrm{TII}$ and $\mathrm{CdI}_{2}$ was selected to be 1:1. Fig. 4 shows the SEM images of the $\mathrm{TlCdI}_{3}$ obtained in the presence of different surfactants. It can be observed that agglomerated nanostructures with different shapes and sizes have been formed in the presence of NaHSal (Fig. 3a), CTAB (Fig. 3b), SDS (Fig. 3c) PVA (Fig. 3d) and Triplex (Fig. 3f). In the presence of NaHSal, CTAB, SDS, Triplex and PVA The morphology of product are not suitable and not regular. The sample obtained in the presence SDS has spherical morphology as shown in Fig. 4 c. The nanoparticles in this figure have more even distribution than other samples. Thus, in our experimental conditions, the ideal surfactant is SDS. Typical histograms of the particle diameters for the samples Nos. 1, 2, 3, 5,6, 7, 8 and 9 are seen in Fig. 5a-h, respectively.

The detailed morphology and particle size of the as-obtained $\mathrm{TlCdI}_{3}$ nanostructures (sample no. 1) was investigated by transmission electron microscopy (TEM). The TEM image (Fig. 5) demonstrates that thallium cadmium iodide nanoparticles with diameter from 10 to $50 \mathrm{~nm}$ have sphere-like shape.

EDS analysis measurement was employed to investigate the chemical composition and purity of as-synthesized $\mathrm{TlCdI}_{3}$ nanostructures. Fig. 6 shows the EDS spectrum of the sample no 1. This figure shows only the presence of $\mathrm{Tl}, \mathrm{Cd}$ and I elements in the product.

The optical absorption spectrum of $\mathrm{TlCdI}_{3}$ nanoparticles represents in Fig. 7a The DRS spectrum was used to further access their quality and electronic structure information. It demonstrates a major absorption peaks about $80 \mathrm{~nm}$ and different low intensity absorption peaks in 100-300 $\mathrm{nm}$. The others absorption bands have been attributed to the impurities or vacancies. The optical band gap of $\mathrm{TlCdI}_{3}$ has been evaluated using the optical density (OD) vs. energy (E) plot (Fig. 7a). The value of band gap energy for this nanoparticle is $\sim 2.9 \mathrm{eV}$. To 
prove the photocatalytic activity of samples for the degradation pollutants, the photocatalytic degradation of MO and MB experiments were performed as a model reaction under UV light irradiation. The percentage of degradation $\% D$ was determined as follows:

$\% D=\frac{A_{0}-A}{A_{0}} \times 100$

Where $A_{0}$ and $A$ are the absorbencies of the liquid sample before and after degradation, respectively. The photocatalytic activity of $\mathrm{TlCdI}_{3}$ powder was investigated by degradation of $\mathrm{MO}$ and $\mathrm{MB}$ as organic pollution. Fig. $7 \mathrm{~b}$ illustrates the UV-Vis spectra of aqueous solution of $\mathrm{MO}$ and $\mathrm{MB}(0.1 \mathrm{mM})$ in presence of $\mathrm{TlCdI}_{3}(0.005 \mathrm{~g} / \mathrm{L})$ at different irradiation times. When $\mathrm{TlCdI}_{3}$ nanopowder is irradiated by light with energy greater than or equal to band-gap, an electron in the valence band could be excited to the conduction band, as a result a hole generated in the valance band. These electron-hole pair that generated by UV-light can also recombines or interacts independently with other molecules in aqueous solution. The holes in the valence band could be reacted with water on the surface of $\mathrm{TlCdI}_{3}$ or hydroxide ions and produced extremely reactive hydroxyl radicals ( $\left.{ }^{\cdot} \mathrm{OH}\right)$ whereas electrons could accept oxygen by adsorption and shaped superoxide radical anion $\left(\mathrm{O}_{2}{ }^{-}\right)$. This radical may form organic peroxides or $\mathrm{H}_{2} \mathrm{O}_{2}$ in presence of organic adsorbent. The hydroxyl radical is a very strong oxidizing agent and aggress the dye molecule to provide the oxidized product. The reactions could be summarized in following reactions [34-35].

$\mathrm{TlCdI}_{3}+h v \rightarrow h^{+}+e^{-}$

$h^{+}+e^{-} \rightarrow$ heat

$\mathrm{H}_{2} \mathrm{O}+h^{+} \rightarrow \mathrm{H}^{+}+\mathrm{OH}^{\circ}$ 
$h^{+}+\mathrm{OH}^{-} \rightarrow \mathrm{OH}$

$e^{-}+\mathrm{O}_{2} \rightarrow \mathrm{O}_{2}^{-}$

$\mathrm{O}_{2}^{-}+\mathrm{HO}_{2}+\mathrm{H}^{+} \rightarrow \mathrm{H}_{2} \mathrm{O}_{2}+\mathrm{O}_{2}$

$\mathrm{O}_{2}^{-}+$organic species $\rightarrow$ organic species $+\mathrm{OO}$

\section{Conclusions}

In this work the nanostructures of $\mathrm{TlCdI}_{3}$ were synthesized by simple mechanical mixture of the reactants method in ambient condition, Accordingly, neither high-temperature, complex chemical reactions nor highvacuum deposition processes are required, contrary to most conventional methods that have been used for sybthesise these materials. The effect of molar ratio of TII: $\mathrm{CdI}_{2}$ and different surfactants on morphology, purity and crystallinity of products were investigated. we could obtain the nanostructures with desired morphology. To the best of our knowledge, it is the first time that nanostructures of $\mathrm{TlCdI}_{3}$ are synthesized in ambient condition also it is the first time that precipitation route are used for the synthesis of these materials. The method is proved to be a new, simple, efficient and quick way.

\section{Acknowledgment}

Authors are grateful to the council of Iran National Science Foundation and University of Kashan for supporting this work by Grant No (159271/5746). 


\section{References:}

[1] Y.-J. Cheng, C.-H. Hsieh, Y. He, C.-S. Hsu, Y. Li, Combination of indene-C60 bis-adduct and cross-linked fullerene interlayer leading to highly efficient inverted polymer solar cells, Journal of the American Chemical Society 132, 17381-17383 (2010).

[2] L.-M. Chen, Z. Xu, Z. Hong, Y. Yang, Interface investigation and engineering-achieving high performance polymer photovoltaic devices, Journal of Materials Chemistry 20, 2575-2598 (2010).

[3] J.H. Seo, A. Gutacker, Y. Sun, H. Wu, F. Huang, Y. Cao, U. Scherf, A.J. Heeger, G.C. Bazan, Improved highefficiency organic solar cells via incorporation of a conjugated polyelectrolyte interlayer, Journal of the American Chemical Society 133, 8416-8419 (2011).

[4] Z. He, C. Zhong, X. Huang, W.Y. Wong, H. Wu, L. Chen, S. Su, Y. Cao, Simultaneous enhancement of open-circuit voltage, short-circuit current density, and fill factor in polymer solar cells, Advanced Materials 23, 4636-4643 (2011).

[5] L. Dou, Y.M. Yang, J. You, Z. Hong, W.-H. Chang, G. Li, Y. Yang, Solution-processed hybrid perovskite photodetectors with high detectivity, Nature communications 5, (2014).

[6] H. Zhu, Y. Fu, F. Meng, X. Wu, Z. Gong, Q. Ding, M.V. Gustafsson, M.T. Trinh, S. Jin, X. Zhu, Lead halide perovskite nanowire lasers with low lasing thresholds and high quality factors, Nature materials 14, 636-642 (2015).

[7] C.C. Stoumpos, C.D. Malliakas, J.A. Peters, Z. Liu, M. Sebastian, J. Im, T.C. Chasapis, A.C. Wibowo, D.Y. Chung, A.J. Freeman, Crystal growth of the perovskite semiconductor $\mathrm{CsPbBr} 3$ : a new material for high-energy radiation detection, Crystal Growth \& Design 13, 2722-2727 (2013). 
[8] S. Yakunin, L. Protesescu, F. Krieg, M.I. Bodnarchuk, G. Nedelcu, M. Humer, G. De Luca, M. Fiebig, W. Heiss, M.V. Kovalenko, Erratum: Low-threshold amplified spontaneous emission and lasing from colloidal nanocrystals of caesium lead halide perovskites, Nature communications 6, (2015).

[9] T. Screen, Platinum group metal perovskite catalysts, Platinum Metals Review 51, 87-92 (2007).

[10] R.A. Jishi, O.B. Ta, A.A. Sharif, Modeling of lead halide perovskites for photovoltaic applications, The Journal of Physical Chemistry C 118, 28344-28349 (2014).

[11] C. Li, X. Lu, W. Ding, L. Feng, Y. Gao, Z. Guo, Formability of ABX3 (X= F, Cl, Br, I) Halide Perovskites, Acta Crystallographica Section B: Structural Science 64, $702-707$ (2008).

[12] A. Hauser, H.U. Güdel, Single-crystal absorption spectra of CsVX3 (X= Cl, Br, I), Chemical Physics Letters $82,72-75(1981)$.

[13] M. Kutsyk, M. Pidzyrailo, On the luminescence of TlCdI 3 crystal, Journal of luminescence 79, 135-141 (1998).

[14] M. Kocsis, Proposal for a new room temperature X-ray detector-thallium lead iodide, Nuclear Science, IEEE Transactions on 47, 1945-1947 (2000).

[15] J. Burness, J. Dillard, L. Taylor, X-ray photoelectron spectroscopic study of cobalt (II) Schiff base complexes and their oxygenation products, Journal of the American Chemical Society 97, 6080-6088 (1975).

[16] C.K. MØLLER, Crystal structure and photoconductivity of caesium plumbohalides, DOI (1958).

[17] G.C. Papavassiliou, A. Patsis, D. Lagouvardos, I. Koutselas, Spectroscopic studies of (C10H21NH3) 2PbI4,(CH3NH3)(C10H21NH3) 2Pb2I7,(CH3NH3) PbI3, and similar compounds, Synthetic metals 57, 38893894 (1993). 
[18] G.C. Papavassiliou, I. Koutselas, Structural, optical and related properties of some natural three-and lowerdimensional semiconductor systems, Synthetic Metals 71, 1713-1714 (1995).

[19] S. Wang, D.B. Mitzi, C.A. Feild, A. Guloy, Synthesis and Characterization of [NH2C (I): NH2] 3MI5 (M= $\mathrm{Sn}, \mathrm{Pb}$ ): Stereochemical Activity in Divalent Tin and Lead Halides Containing Single. 1tbbrac. 110. rtbbrac. Perovskite Sheets, Journal of the American Chemical Society 117, 5297-5302 (1995).

[20] I. Koutselas, D. Mitzi, G.C. Papavassiliou, G. Papaioannou, H. Krautscheid, Optical and related properties of natural one-dimensional semiconductors based on PbI and SnI units, Synthetic metals 86, 2171-2172 (1997).

[21] B.R. Vincent, K.N. Robertson, T.S. Cameron, O. Knop, Alkylammonium lead halides. Part 1. Isolated PbI64-ions in (CH3NH3) 4PbI62H2O, Canadian journal of chemistry 65, 1042-1046 (1987).

[22] V.W.-W. Yam, Y.-L. Pui, K.-K. Cheung, Synthesis, photophysics, and electrochemistry of dinuclear cadmium (II) diimine complexes with bridging chalcogenolate ligands. X-Ray crystal structures of [(phen) $2 \mathrm{Cd}$ ( $\mu$-SC 6 H 4 CH 3-p)] 2 (PF 6) 2 and [(phen) 2 Cd ( $\mu$-SeC 6 H 5)] 2 (PF 6) 2, New Journal of Chemistry 23, 1163-1169 (1999).

[23] C.C. Stoumpos, C.D. Malliakas, M.G. Kanatzidis, Semiconducting tin and lead iodide perovskites with organic cations: phase transitions, high mobilities, and near-infrared photoluminescent properties, Inorganic chemistry 52, 9019-9038 (2013).

[24] A. Ataie, I. Harris, C. Ponton, Magnetic properties of hydrothermally synthesized strontium hexaferrite as a function of synthesis conditions, Journal of materials science 30, 1429-1433 (1995).

[25] J. Fang, J. Wang, L.M. Gan, S.C. Ng, J. Ding, X. Liu, Fine Strontium Ferrite Powders from an Ethanol-Based Microemulsion, Journal of the American Ceramic Society 83, 1049-1055 (2000). 
[26] A. Ataie, S. Heshmati-Manesh, Synthesis of ultra-fine particles of strontium hexaferrite by a modified coprecipitation method, Journal of the European Ceramic Society 21, 1951-1955 (2001).

[27] F. Ansari, A. Sobhani, M. Salavati-Niasari, Sol-gel auto-combustion synthesis of PbFe12O19 using maltose as a novel reductant, RSC Adv 4, 63946-63950 (2014).

[28] F. Ansari, F. Soofivand, M. Salavati-Niasari, Utilizing maleic acid as a novel fuel for synthesis of $\mathrm{PbFe} 12 \mathrm{O}$ 19 nanoceramics via sol-gel auto-combustion route, Materials Characterization 103, 11-17 (2015).

[29] F. Ansari, A. Sobhani, M. Salavati-Niasari, Facile synthesis, characterization and magnetic property of CuFe 12 O 19 nanostructures via a sol-gel auto-combustion process, Journal of Magnetism and Magnetic Materials 401, (2016) 362-369.

[30] F. Ansari, M. Bazarganipour, M. Salavati-Niasari, NiTiO 3/NiFe 2 O 4 nanocomposites: Simple sol-gel auto-combustion synthesis and characterization by utilizing onion extract as a novel fuel and green capping agent, Materials Science in Semiconductor Processing 43, 34-40 (2016).

[31] D. Zaitsev, S. Kushnir, P. Kazin, Y.D. Tretyakov, M. Jansen, Preparation of the $\mathrm{SrFe}_{12} \mathrm{O}_{19}$-based magnetic composites via boron oxide glass devitrification, Journal of magnetism and magnetic materials 301, 489-494 (2006).

[32] R. Arendt, Liquid-phase sintering of magnetically isotropic and anise by the reaction of $\mathrm{BaFe}_{2} \mathrm{O}_{4}$ with $\mathrm{Fe}_{2} \mathrm{O}_{3}$, J Solid State Chem 8, 339 (1973).

[33] A. Sobhani, M. Salavati-Niasari, A new simple route for the preparation of nanosized copper selenides under different conditions, Ceramics International 40, 8173-8182 (2014). 
[34] F. Fang, L. Kong, J. Huang, S. Wu, K. Zhang, X. Wang, B. Sun, Z. Jin, J. Wang, X.-J. Huang, Removal of cobalt ions from aqueous solution by an amination graphene oxide nanocomposite, Journal of hazardous materials 270, 1-10 (2014).

[35] S. Sakthivel, B. Neppolian, M. Shankar, B. Arabindoo, M. Palanichamy, V. Murugesan, Solar photocatalytic degradation of azo dye: comparison of photocatalytic efficiency of $\mathrm{ZnO}$ and $\mathrm{TiO}$ 2, Solar Energy Materials and Solar Cells 77, 65-82 (2003).

[36] S. S. Shinde, P. S. Shinde, C. H. Bhosale, K. Y. Rajpure, Zinc oxide mediated heterogeneous photocatalytic degradation of organic species under solar radiation, J. Photochem. Photobiol B 104, $425-433$ (2011). 


\section{Figure captions}

Fig. 1. XRD patterns of samples prepared: (a) with ratio of $1: 1$ of $\mathrm{TlI}: \mathrm{CdI}_{2}$ (sample no. 1) , (b) ratio of $1: 2$ TlI: $\mathrm{CdI}_{2}$ (sample no. 2), (c) ratio of 2:1 of TlI:CdI 2 (sample no. 3), (d) ratio of 1:0.75 of TlI:CdI 2 (sample no. 4).

Fig. 2. XRD patterns of samples prepared with 1:1 ratio of TlI:CdI $\mathrm{Cl}_{2}$, in the presence of: (a) NaHsal (sample no. 5),

(b) CTAB (sample no. 6), (c) SDS (sample no. 7), (d) triplex (sample no. 8) and (f) PVA (sample no. 9).

Fig. 3. SEM images of $\mathrm{TlCdI}_{3}$ nanostructures prepared with different ratios of $\mathrm{TlI}: \mathrm{CdI}_{2}$ : (a) with ratio of 1:1 (sample no. 1), (b) ratio of 1:2 (sample no. 2), (c) ratio of 2:1 (sample no. 3), (d) ratio of 1:0.75 (sample no. 4).

Fig. 4. SEM images of $\mathrm{TlCdI}_{3}$ prepared with 1:1 ratio of $\mathrm{TlI}: \mathrm{CdI}_{2}$, in the presence of: (a) NaHsal (sample no. 5),

(b) CTAB (sample no. 6), (c) SDS (sample no. 7), (d) triplex (sample no. 8) and (f) PVA (sample no. 9).

Fig. 5. Particle size distribution of samples Nos. (a) 1, (b) 2, (c) 3, (d) 5, (e) 6, (f) 7, (g) 8 and (h) 9.

Fig. 6. TEM images of $\mathrm{TlCdI}_{3}$ nanostructures prepared with ratio of 1:1 of $\mathrm{TlI}: \mathrm{CdI}_{2}$ (sample no. 1).

Fig. 7. EDS patterns of $\mathrm{TlCdI}_{3}$ nanostructures (sample no. 1).

Fig. 8. (a) DRS spectrum (b) optical density $(\alpha h v)^{2}$ vs. energy (c) UV-Vis spectra of photodegradation of MO and $\mathrm{MB}$ with $\mathrm{TlCdI}_{3}$ as a function of time.

Table 1. The reaction conditions of $\mathrm{TlCdI}_{3}$ synthesized in this work.

Scheme 1. shows a schematic diagram of the formation process of the $\mathrm{TlCdI}_{3}$ nanostructures. 


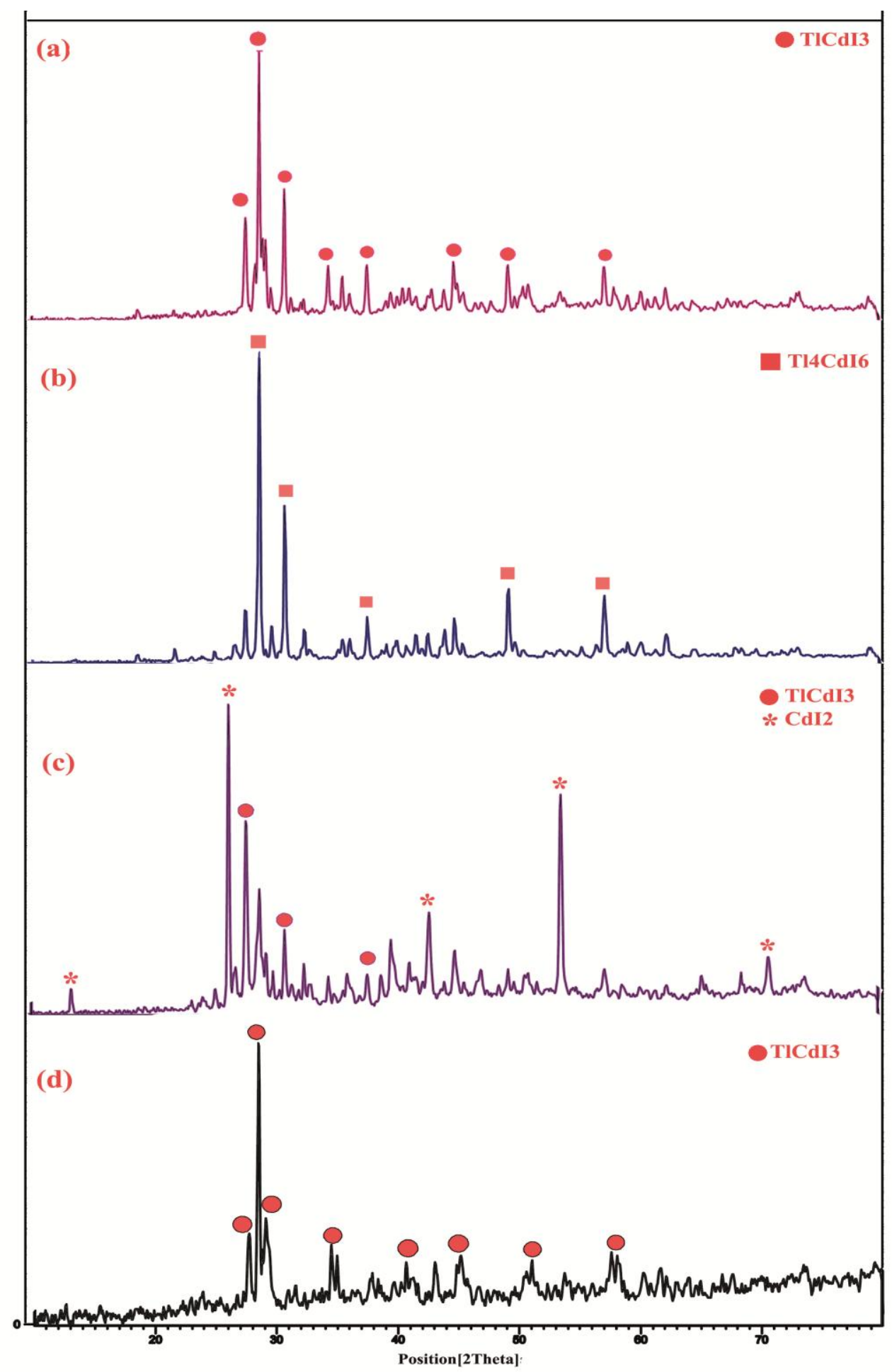

Fig 1. 


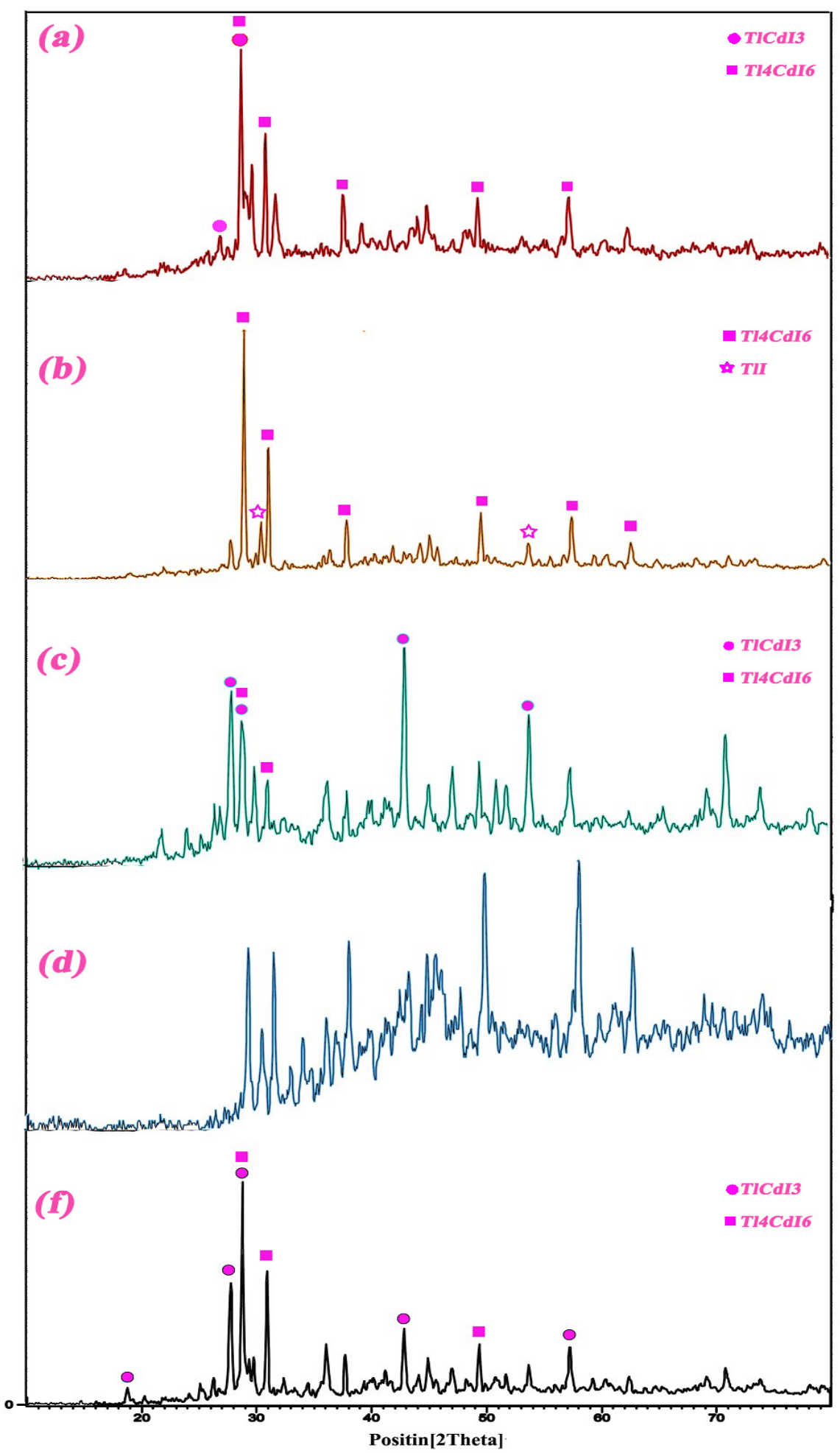

Fig 2. 


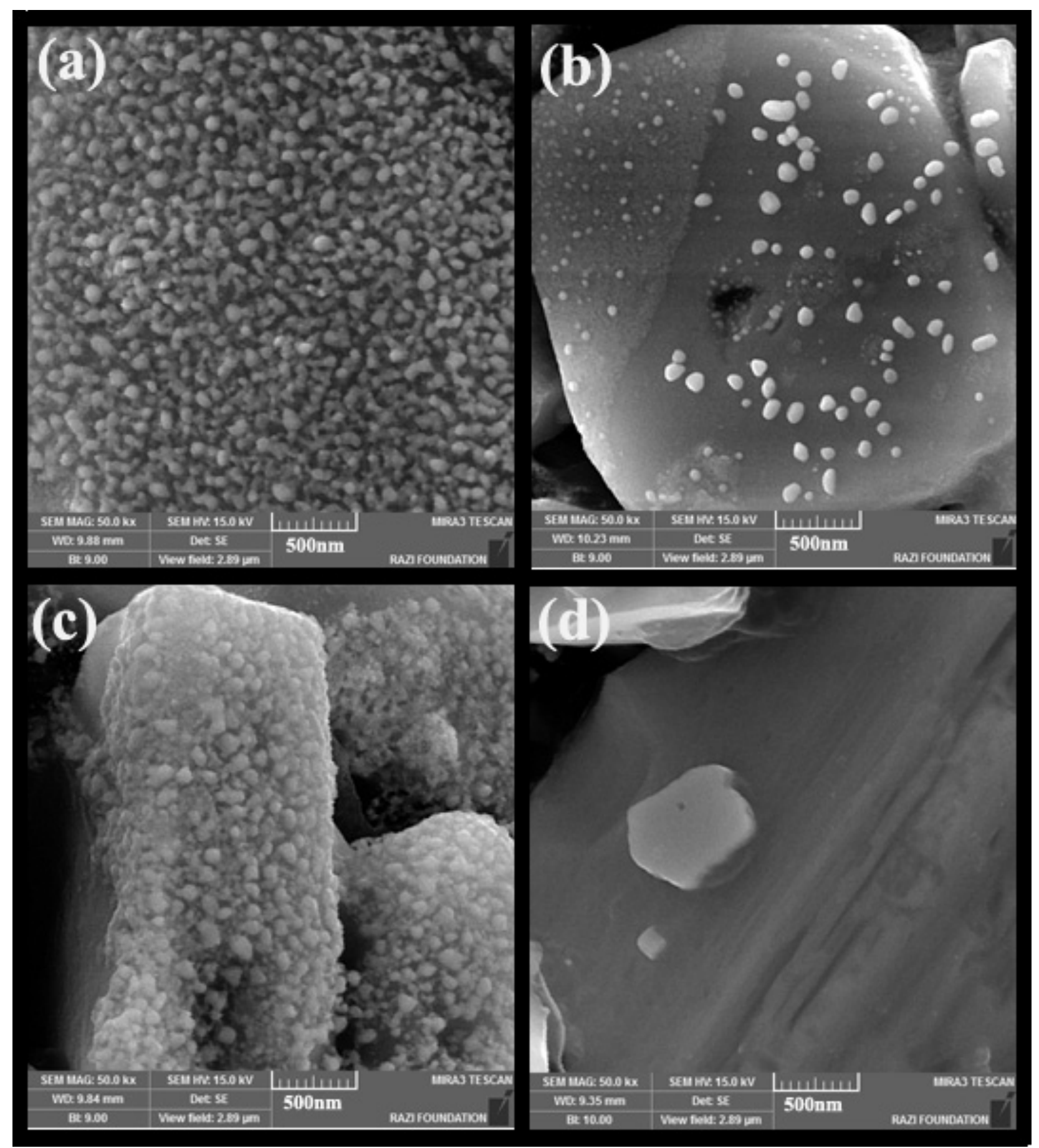

Fig 3. 


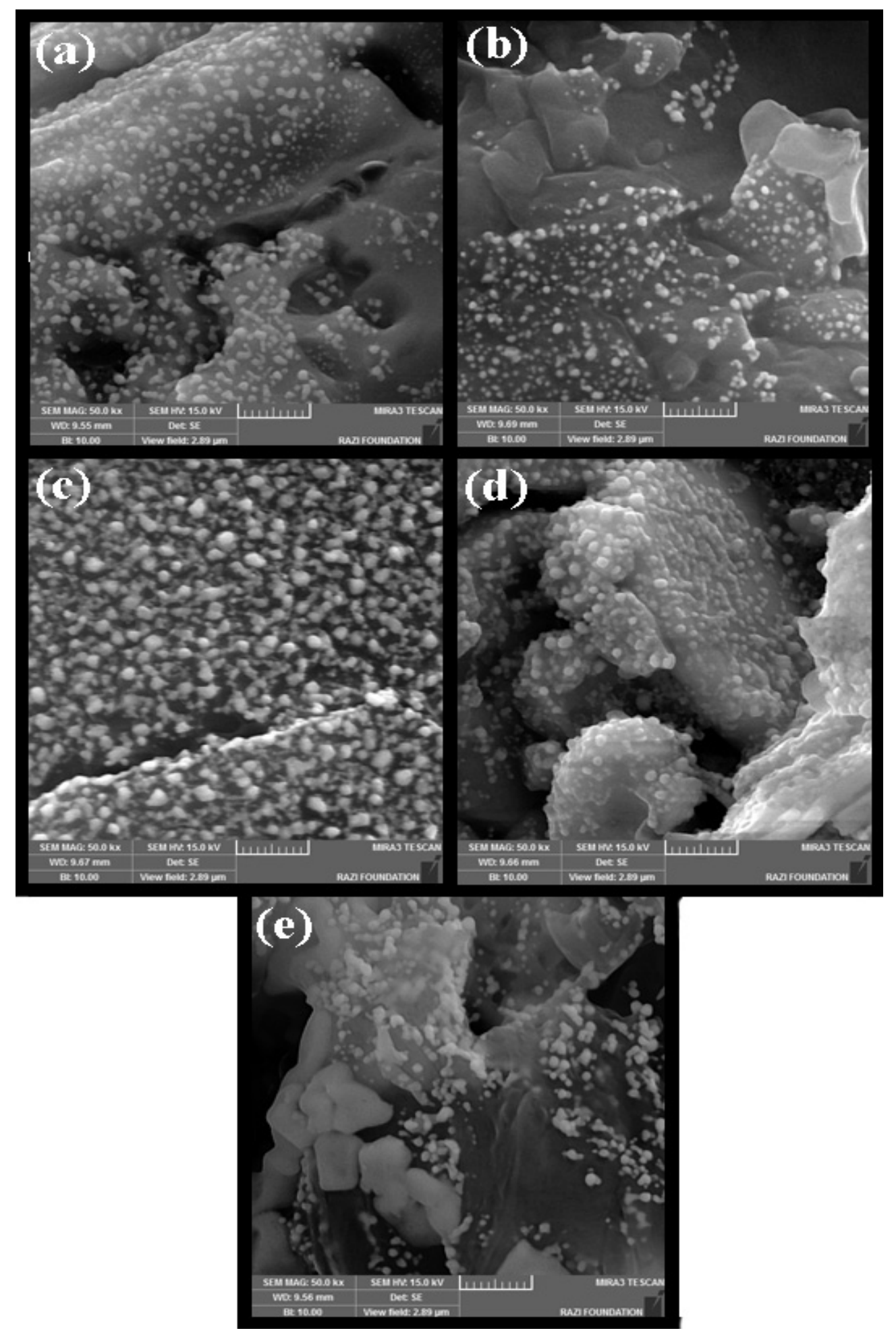

Fig 4. 

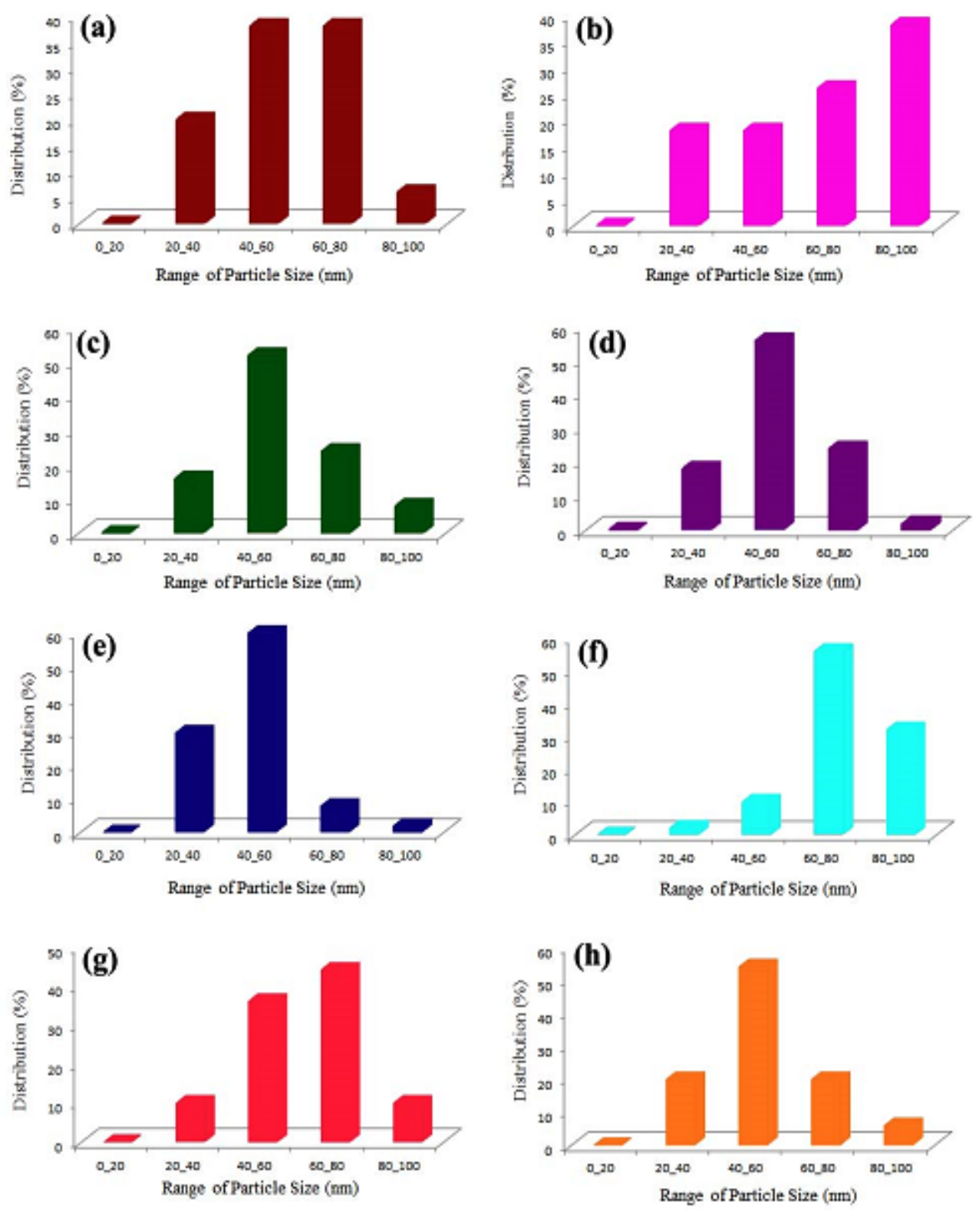

Fig. 5 


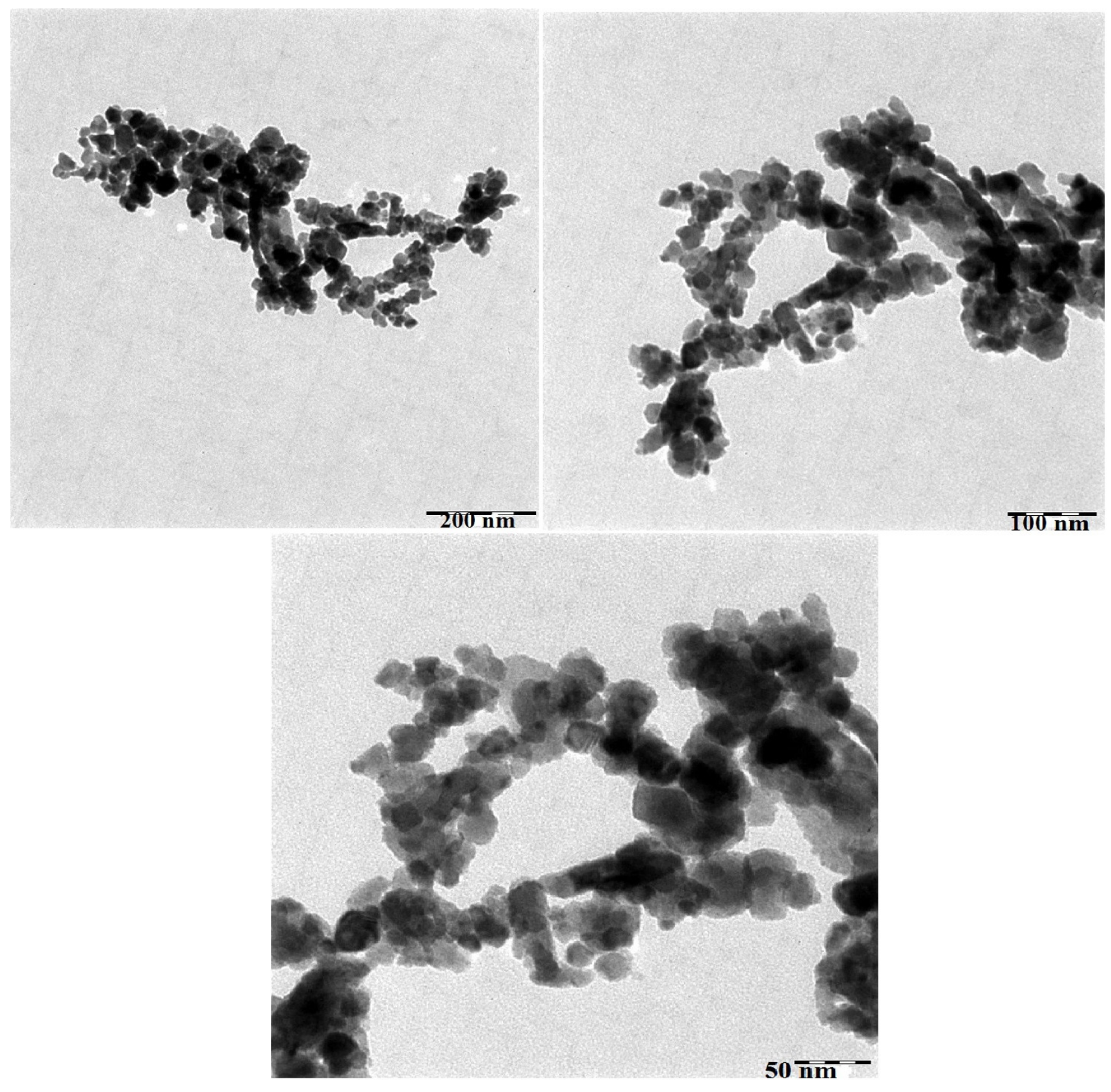

Fig 6. 


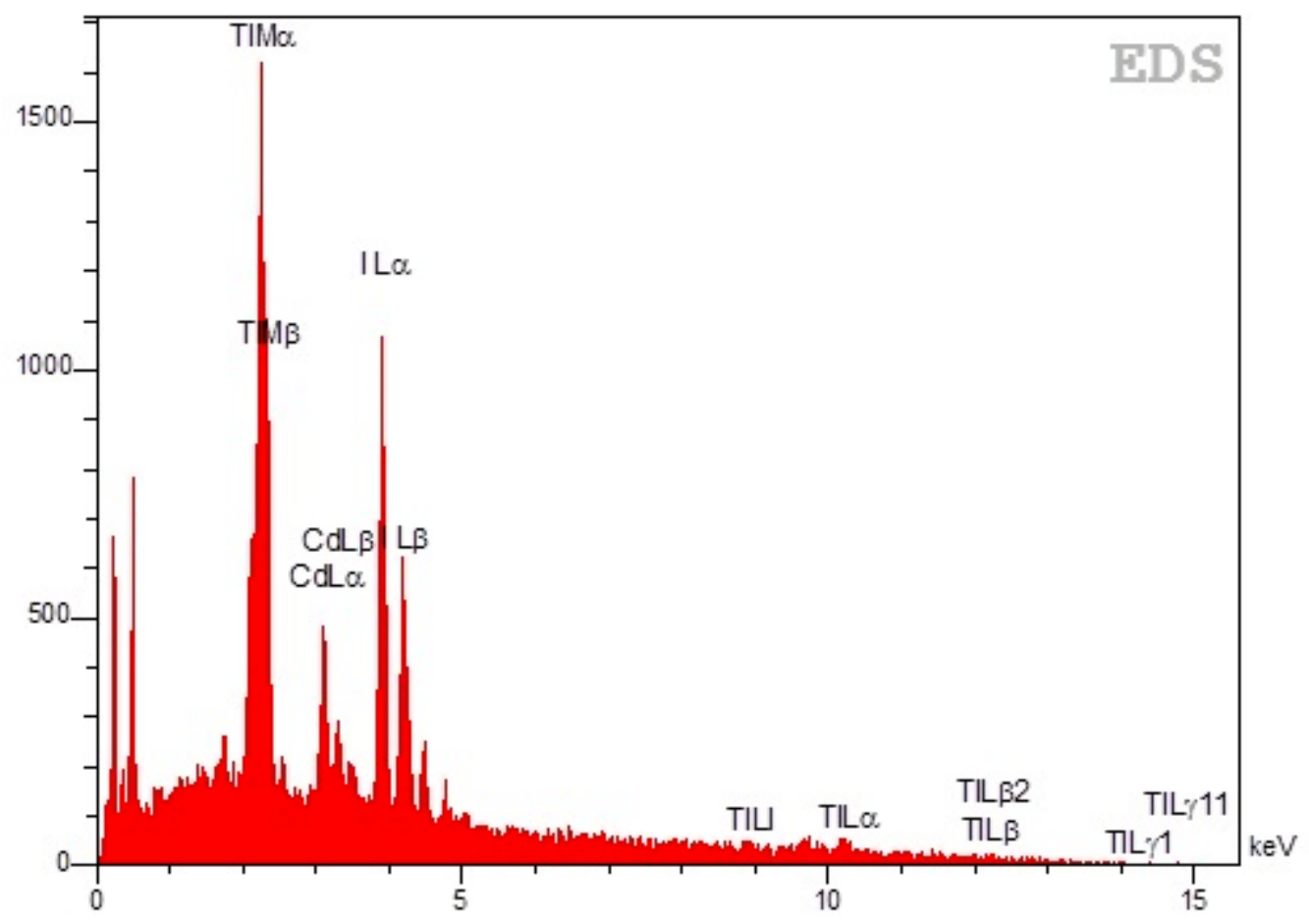

Fig. 7. 

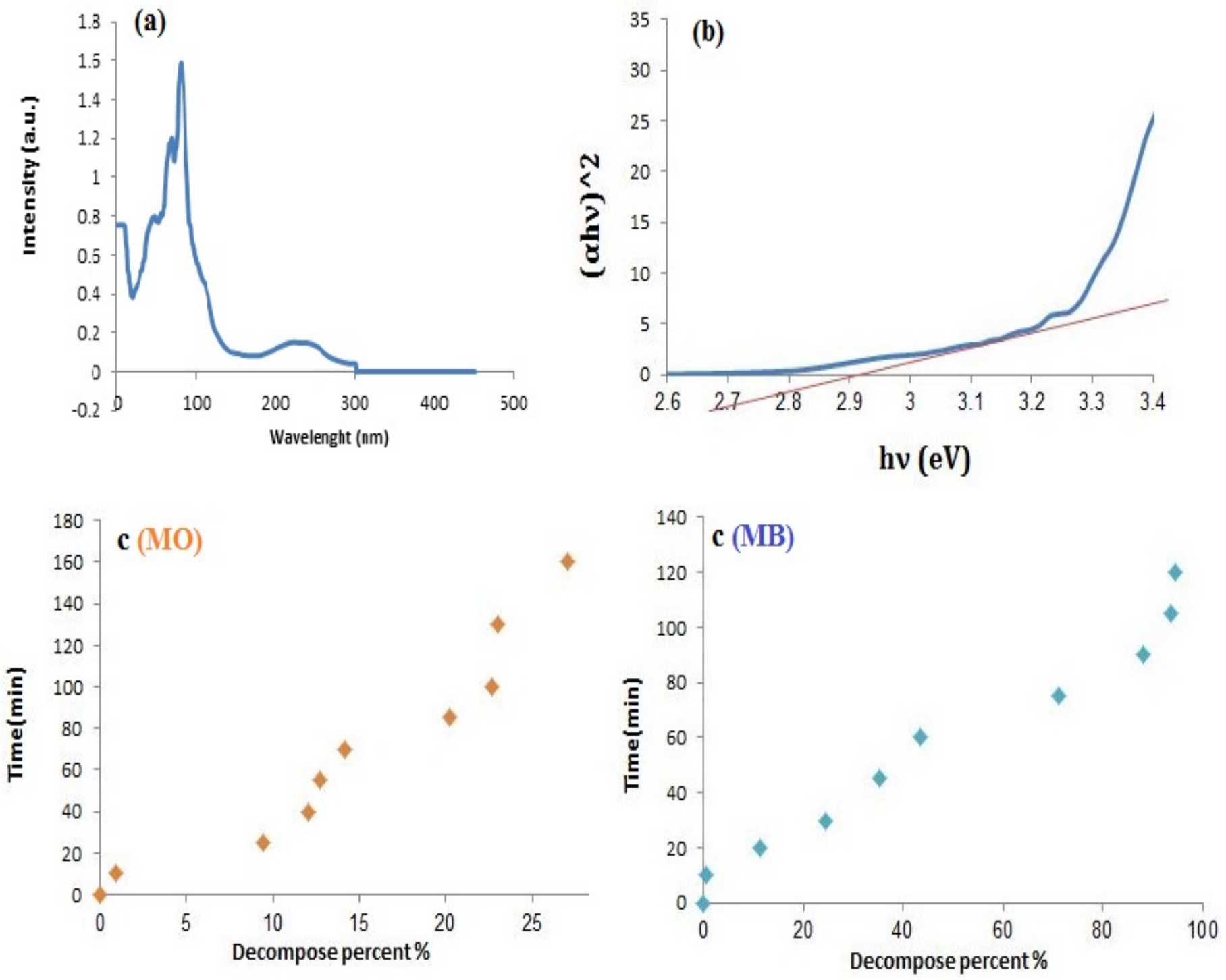

Fig. 8. 
Table 1.

\begin{tabular}{lll}
\hline Sample. no & Precursors Ratio & Surfactant \\
\hline 1 & $\mathrm{TlI}+\mathrm{CdI}_{2}$ & - \\
2 & $\mathrm{TlI}+2 \mathrm{CdI}_{2}$ & - \\
3 & $2 \mathrm{TlI}+\mathrm{CdI}_{2}$ & - \\
4 & $\mathrm{TlI}+0.75 \mathrm{CdI}_{2}$ & - \\
5 & $\mathrm{TlI}+\mathrm{CdI}_{2}$ & $\mathrm{NaHSal}$ \\
6 & $\mathrm{TlI}+\mathrm{CdI}_{2}$ & $\mathrm{CTAB}$ \\
7 & $\mathrm{TlI}+\mathrm{CdI}_{2}$ & SDS \\
8 & $\mathrm{TlI}+\mathrm{CdI}_{2}$ & Triplex \\
9 & $\mathrm{TlI}+\mathrm{CdI}_{2}$ & PVA \\
\hline
\end{tabular}




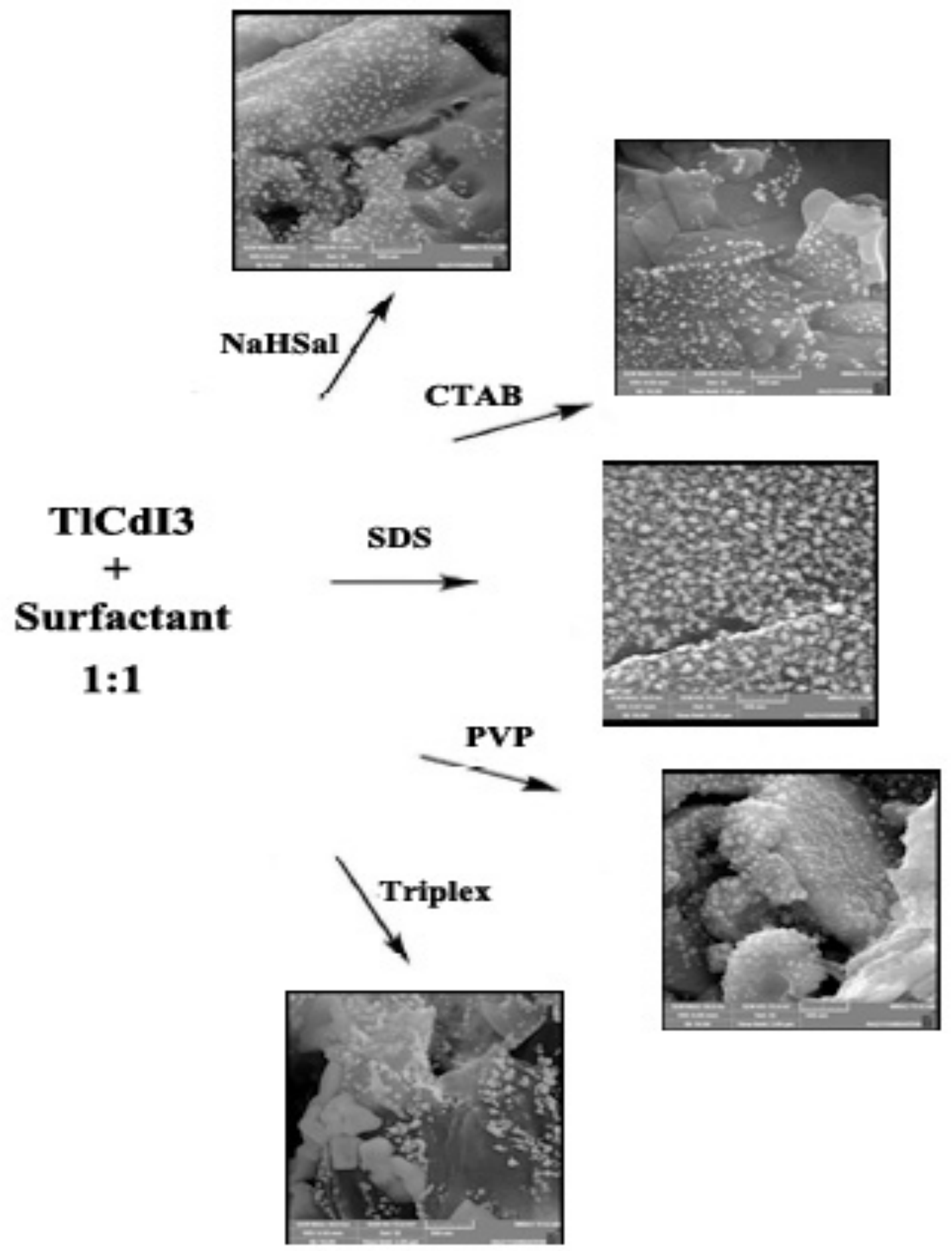

Scheme 1. 